\title{
LA SOCIEDAD CIVIL EN EUROPA OCCIDENTAL
}

\author{
Salvador Giner \\ Luis Moreno
}

\section{Introducción}

Europa Occidental es la cuna de la sociedad civil. Poseerla es uno de sus rasgos históricos más sobresalientes. La sociedad civil es aquella esfera históricamente constituida de derechos individuales, libertades y asociaciones voluntarias, cuya autonomía y mutua concurrencia en la persecución de sus intereses e intenciones privados quedan garantizados por el estado y la ley. Las instituciones públicas y sus representantes se abstienen, de modo explícito, de intervenir políticamente en la vida interna del ámbito de actividades humanas establecido por la sociedad civil. ${ }^{1}$

La sociedad civil es una entidad histórica surgida de la civilización burguesa europea que posee cinco rasgos característicos: individualismo, privacidad, mercado, pluralismo y clase. El individuo es la unidad suprema de la sociedad civil. La soberanía del hombre individual que trajo la civilización burguesa europea entrañó la fe en su primacía moral, filosófica, epistemológica y hasta ontológica. $\mathrm{La}$ sociedad civil vino a entenderse, de tal manera, como el ámbito adecuado para la plena realización del individuo como ciudadano libre, consciente y a la búsqueda de su felicidad mundana. Así lo proclamaron las declaraciones solemnes del liberalismo inicial revolucionario.

No existe ninguna sociedad civil paradigmática en el "mundo real". Existen en cambio varias sociedades civiles, todas distintas las

[1] Naturalmente, esta es la definición ideal típica de sociedad civil. En el resto de este ensayo concretaremos sus limitaciones y límites reales. Cf. los trabajos de Salvador Giner, Ensayos Civiles, (Madrid: Península, 1987), pp. 56-62 y El destino de la libertad, (Madrid: Espasa Calpe, 1987), pp. 49-56. También, N. Bibbio, Stato, governo, societa, (Turin: Einaudi, 1985), especialmente cap. 2, "La societa civile", pp. 23-42. 
unas de las otras. Algunas son más maduras, otras lo son menos. Así, puede aseverarse que Gran Bretaña posee una sociedad civil "fuerte" en contraste con las de los países de la Europa Meridional, como Grecia o España. Esta idea de la fortaleza o debilidad de la sociedad civil se ha hecho frecuentemente extensiva a otros países, como los de Hispanoamérica, con el fin de interpretar su historia reciente: su sociedad civil muy débil explicaría desequilibrios, dictaduras e intervencionismos estatales, así como endémicas guerras intestinas.

Dentro del pensamiento liberal clásico, la sociedad civil ha sido considerada como el ámbito en el que se llevaban a cabo los intereses individuales de los hombres dentro de un marco competitivo, contractual, capaz de permitir la privacidad y la intimidad, así como el disfrute de los derechos y la propiedad privados. Por su parte la teoría marxista tradicional ha postulado la primacía de lo económico sobre lo político. De esta manera, la sociedad civil ha sido identificada por ella y ante todo como el reino de las clases sociales, la desigualdad y la explotación, y como el sustento social del nuevo estado moderno. La visión neomarxista inaugurada por Gramsci, aún delimitando a efectos metodológicos "estado" y "sociedad civil", observa empero un entrelazamiento de ambos como partes integrantes de una sociedad política única. $^{2}$

\section{El origen de la sociedad europea}

La civilización europea, que en buena parte hunde sus raíces en la tradición religiosa judeocristiana, se caracteriza hoy sin embargo por su secularización. La civilización europea ha creado, a lo largo de su historia moderna, una tradición específica de innovación política, técnica y cultural, a través de la progresiva aunque muy desigual racionalización de las condiciones de vida. ${ }^{3}$ Ese complejo proceso condujo a la llamada modernidad. Históricamente sólo en Europa tuvo lugar la conjunción de tendencias que habría de conducir a ese

[2] Véase A. Gramsci, Note sulMacchiavelli, (Turtn: Einaudi, 1966), pp. 230y A. M. Macchiocchi, Pour Gramsci, (Paris: Seuil, 1974), p. 163.

[3] La transición de la sociedad silvestre a la civilizada es el tema que confirió notorieđad a la obra pionera del escocés Adam Ferguson, Un Ensayo sabre la Historia de la Sociedad Civil, (Madrid: Instituto de Estudios Políticos, 1974) ed. en inglés: An Essay on the History of Human Society, (Edimburgo: Edinburgh University Press, 1966). Para las complejidades del proceso đe racionalización, cf. G. Marramao, Podery Secularización, (Barcelona: Península, 1989). 
estado de cosas. Sólo en Europa se desarrolló, a partir del Renacimiento, una civilización a la vez burguesa, capitalista, crecientemente secular, en la que la esfera política quedaba claramente separada de la religiosa, y cuya economía se sustentaba en el cálculo de los riesgos, la acumulación permanente de capital e innovaciones técnicas y la empresa privada. En Europa, y sobre esta plataforma social, se levantó una red de estados soberanos en competencia permanente entre sí, sin que ninguno consiguiera anular a los demás. Algunos de ellos crearon imperios mundiales, pero la incapacidad de que alguno de ellos anulara a todos los demás, a través de un imperio totalitario y duradero, permitió la subsistencia de sus sociedades civiles respectivas. $^{4}$

La persistencia de un sistema europeo de estados soberanos es, históricamente, un hecho crucial explicativo de sus sociedades civiles. La propia civilización burguesa debe su existencia al sistema europeo de estados. Desde la orientalización y descomposición del Imperio romano, que frustró su propio y posible aburguesamiento, hasta el presente, Europa ha estado políticamente fragmentada aunque no ha perdido su unidad cultural y de civilización. Los intentos de unificación bajo un sólo imperio -Carlomagno, Don Carlos de Hausburgo, Napoleón- fueron efímeros y no cuajaron. Para colmo el último de ellos, el III Reich nazi alemán, estuvo basado en la pura barbariey vino a ser la quinta esencia de lo más destructivo y peligroso que puede llegar a producir también la dinámica occidental.

Lo que diferencia, además, a la dinámica europea de otras civilizaciones, como la china o la hindú, es que logró extenderse hegemónicamente por los cinco continentes y se transformó, por ende, en elemento universal de la dinámica mundial. Con ello logró exportar algunos de sus componentes, como el de la sociedad civil, a otros lugares, aunque no siempre con mucho éxito. $\mathrm{El}$ hecho es que poseer una sociedad civil no es hoy una realidad exclusiva de los pueblos europeos.

Con la llegada de la era de las revoluciones surgió una conciencia en varios sectores estratégicos de las clases burguesas occidentales que las estimuló para moldear el mundo según sus designios e inte-

[4] Cf. J. Hall, Poderes y libertades, (Barcelona: Península, 1987). 
reses. Esa fase de transición de la historia natural a la historia deseada puede situarse en un período comprendido entre la Revolución puritana inglesa de 1648 y la bolchevique rusa de 1917. Entre ambas se produjeron la norteamericana de 1775 y la francesa de 1789. Con la excepción de la rusa -el imperio zarista poseía una đébil sociedad burguesa y, por ende, los demás países presenciaron una consolidación del ámbito de autonomías individuales, institucionales y asociativas que constituye toda sociedad civil.

En la gran era de incubación anterior a la modernidad hubo empero un triunfo silencioso de la burguesía. Un triunfo poco claro y a menudo ambivalente, que estuvo jalonado de esfuerzos por parte de los burgueses para acceder y fundirse con los estamentos nobles o aristocráticos que dominaban la vida social. Durante los siglos anteriores a la era industrial se fraguó en Europa un sistema singular de desigualdad social que consistió en una orden de libertades, entendidas estrictamente como privilegios. Homenaje, señorío, vasallaje y linaje eran los cuatro puntos cardinales del orden social de la desigualdad premoderna, que descansaban sobre una concepción señorial de la propiedad, esencialmente de la tierra.

Puede afirmarse que cuando más feudal ha sido una sociedad en su pasado, más burguesa y moderna ha resultado posteriormente. Las partes de Europa que más se acercan a la imagen de una "pura" sociedad feudal, han sido aquéllas que habían de ser las cunas de la modernidad: el Franco Condado, los Países Bajos, Inglaterra, Francia. En la Europa meridional, las zonas de mayor pujanza burguesa en siglos posteriores, Lombardía y Piamonte por una parte, y Cataluña por otra, fueron también en el período premoderno zonas de feudalismo maduro y avanzado. Paradójicamente, las que mayores rasgos de tipo feudal han arrastrado hasta casi nuestros días -Italia meridional, Andalucía, partes de Hispanoamérica- tuvieron una feudalidad harto imperfecta. Esta relación inversamente proporcional ayuda a explicar las vicisitudes históricas de las diversas sociedades civiles europeas.

En todo caso, y aún teniendo presente la complejidad de los distintos análisis, es posible atribuir a esa cómoda abstracción que llamamos burguesía el posible protagonismo del largo proceso de 
modernización que abarca desde el otoño del Medioevo hasta la Gran Guerra de 1914.

\section{La desigualdad social en La Europa del siglo XX}

Examinamos a continuación, aunque muy en escorzo, varias de las dimensiones más sobresalientes del cambio socioestructural percibible en los países europeos occidentales en los últimos decenios. El marco en que todo ello será analizado es el de una poderosa sociedad civil, en pugna y a la vez mutua dependencia con unos estados y aparatos públicos en constante expansión.

\subsection{Movilidad social}

Dos parecen haber sido los aspectos más importantes en relación a la movilidad social reciente en Europa:

a) El incremento de la tasa de movilidad social producida por el triple desarrollo económico, educativo y tecnológico. Este tipo ha sido generado, a su vez, por la institucionalización de la innovación por parte de la cultura europea.

b) La creciente importancia del logro profesional, como fuente de rango social, en contraste con los criterios adscriptivos de categoría social. Tal logro se mide por la consecuencia y acopio de títulos y patentes a través de la educación especializada.

Respecto a los componentes presentes en el cambio estructural de la movilidad colectiva pueden enumerarse suscintamente el crecimiento del empleo industrial y de servicios, la especialización, subdivisión y multiplicación de la calificación profesional, el aumento de las categorías profesionales de mayor rango, la burocratización y la organización del trabajo especializado en unidades administrativas de gran tamaño. ${ }^{5}$ Por lo tanto, y sin que haya desaparecido del todo la sociedad burguesa tradicional, nos encontramos con una vasta reestructuración social a base de redes ocupacionales y titulaciones, por una parte, y empresas, corporaciones y burocracias, por otra.

[5] Cf. W. E. Moore, "Changes in Occupational Structures", en: N. J. Smelser \& S. M. Lipset (eds.), Social Structure and Mobility in Economic Development, (Londres: Routledge \& Kegan Paul, 1966), pp. 194-212. 
Aunque para la mayoría de los países europeos occidentales ha podido detectarse una cierta correlación entre la expansión educativay el crecimiento económico, no debe colegirse mecánicamente que el mercado de trabajo haya requerido siempre una instrucción mayor de la fuerza de trabajo. De hecho, caben apreciarse discontinuidades entre el desarrollo económico y educativo que indican que dicha relación ha sido más contingente que necesaria. En cualquier caso, y dados los procesos de homogeneización y de limitación de los canales tradicionales de movilidad en la Europa posterior a la Segunda Guerra Mundial, la educación, la instrucción y la pericia han predominado como medios de ascensión social pero también, en casos significativos, como procesos para mantener la desigualdad o hasta para crear nuevas formas de ella.

La expansión educativa y la de las clases medias, en general, ha trocado la tradicional forma piramidal, característica de la primera etapa industrial europea, por una figura social de tipo más romboide. El crecimiento numérico de las clases medias que se localizan en la zona intermedia de la distribución del poder y los ingresos cabe ser atribuido al aumento de la burocratización y la llamada clase "servicio". 6 Por otra parte, el incremento del pluralismo político en la Europa occidental ha traído consigo una multiplicación, y hasta fragmentación, de las élites tradicionales, mientras que las clases medias -escudadas en su nivel de estudios y conocimientos- han venido a ser la cantera principal de la clase política. El poder político europeo es, en buena medida, mesocrático. Hasta en sindicatos y partidos de izquierda -socialistas o comunistas- es notoria hoy la presencia de profesionales y técnicos de clase media.

La generalización de una mayor riqueza, resultado de una producción económica en expansión, redujo en los decenios de los años 50,60 y parte de los 70 las diferencias en la renta entre las clases sociales y estimuló, así mismo, una cultura basada en el consumo de bienes y servicios. Ello resultó en una mayor convergencia en los estilos de vida de amplias capas sociales y hasta de países y regiones diversos que, si acaso, se ha visto alterada tras la recesión económica de mediados de los 70 y la progresiva polarización de una sociedad

[6] Cf. R. Dahrendorf, "Recent Changes in the Class Structure of European Societies", en: Daedalus, Invierno 1964, p. 235 y passim. 
que no puede incorporar a una minoría importante de marginados sociales. Consecuencia de esto último es que la sociedad civil europea posee una zona articulada, próspera y plena de asociaciones y movimientos sociales organizados frente a otra mucho más pasiva, subordinada y, en algunos casos, hasta a la deriva.

La movilidad del poder debería ser enmarcada con referencia a tres de sus aspectos más característicos: (a) la autoridad y poder políticos; (b) el poder ocupacional; y (c) la influencia. Los estudios concentran frecuentemente sus análisis en el aspecto ocupacional del poder. Es decir, aquella movilidad relacionada con los agentes de la politeya: la clase política formada por los representantes políticos (diputados, ministros, alcaldes, consejeros regionales), los altos funcionarios y, en algunos países, los integrantes de las cúpulas militares y los miembros de la judicatura. La tesis de la creciente meritocracia, que también enlaza con este aspecto ocupacional del poder, postula que la selección y el reclutamiento de las élites políticas ocurre principalmente bajo el criterio de una liza permanente en el marco del estado liberal democrático connatural a la civilización europea. Por otra parte el prestigio, la remuneración y la promoción inherente a la carrera de los funcionarios en la Europa occidental aparecen como importantes determinantes en el carácter semiaristocrático de los funcionarios alemanes, franceses y británicos en contraste con el carácter más abierto de sus colegas italianos, belgas o suizos. Sea como fuere, el poder ocupacional es más conforme con los factores estrictamente políticos o de cargo que con los genuinamente económicos. La creciente expansión estatal ha dado así lugar a una "burguesía de estado" desvinculada de aquella sociedad civil, cuya burguesía mercantil, industrial y financiera tanto llegó a pesar históricamente en la conformación del poder político.

La prosperidad generada en Europa occidental a partir de 1945 ha tenido como consecuencia mayores niveles de renta y de servicios a las clases necesitadas a través del aparato público asistencial. Ello ha incidido en una mayor movilidad de rango ascendente para grandes sectores de las poblaciones europeas. Sin embargo, siguen existiendo rasgos materiales e inmateriales que continúan 
manteniendo la discriminación social. Cabe destacar entre los inmateriales el linaje en Francia o la República Federal de Alemania, o el acento lingüístico en Gran Bretaña. Bien es verdad que, aunque dichos criterios de tipo simbólico sirven para diferenciar a las élites tradicionales del resto de la población, no son siempre transpolables a los estratos medios y bajos de la sociedad. Así, las diferencias de rango en dichos estratos no parecen sustentarse en una ausencia de posibilidades materiales para adoptar un tipo de vida superior, sino en una miríada de matices intangibles relacionados con el vestir, las aficiones en el tiempo libre y otros signos exteriores. Más tangible sin embargo es la reproducción de la mesocracia, mediante su control indirecto de la meritocracia a través de la importancia crucial de la educación y las titulaciones académicas. La meritocracia puede llegar a cristalizar por medio de una red de grandes écoles -como es el caso de Francia- que genera una nueva "nobleza" de privilegiados al servicio del sector público.?

\subsection{Las nuevas clases asalariadas}

Superadas las viejas rigideces doctrinales que postulaban la "unidad de la clase trabajadora", ${ }^{8}$ cabe resaltar la diferenciación intraclasista de la amplia clase trabajadora y su correspondiente subdivisión en cuatro grandes estratos sociales: (a) Los trabajadores tecnológicamente calificados; (b) Los trabajadores de conocimientos medios, (c) Los trabajadores sin calificar y (d) Los trabajadores en paro crónico. En las sociedades europeas, la conciencia de clase coexiste con la conciencia del estrato al que se pertenece. Dicha agregación se articula mediante la percepción de pertenencia a un grupo ocupacional y, mediante dicha pertenencia grupal, a la variada clase trabajadora en su conjunto. De otra parte, los datos que se poseen indican que no existe una relación lineal entre roles ocupacionales y status.

[7] Cf. P. Bourdie, La noblesse d'état, (París: Editions de Minuit, 1989) y M. Young, The Rose of the Meritocracy, (Harmondsworth: Penguin, 1971) 1a. ed. 1958.

[8] Dicha formulación unitaria fue criticada por Ralf Dahrendorf en su obra, Class and Class Conflict in Industrial Society, (Londres: Routledge \& Kegan Paul, 1959) Edición en castellano: Las clases sociales y su conficto en la sociedad industrial, (Madrid: Rialp, 1962). Dahrendorf ha postulado que, en la moderna sociedad industrial, la distancia que separa a los tres estratos que componen la clase trabajadora no puede ser eliminada por la mera profesión de la solidaridad que pueda darse entre ellos. 
El espectacular cambio tecnológico que ha tenido lugar en los sistemas productivos de los países de la Europa occidental, así como las nuevas tendencias culturales, son responsables en gran medida de una estructura ocupacional compleja y fluida, con su consiguiente impacto en una abigarrada proliferación de diversos estratos sociales.

Cabe distinguir dos rasgos esenciales en la nueva clase trabajadora de la Europa Occidental que, a su vez, se configuran como tendencias sociales opuestas. De una parte, se ha observado una acentuación en las diferencias de los tres grandes estratos que la constituyen. Ello se manifiesta en la creciente disparidad entre los grupos formados por la mayor parte de los trabajadores altamente calificados, ${ }^{9}$ de un lado, y de la clase obrera sin calificar, de otro. Ello se combina con la casi completa desaparición de un proletariado de tipo tradicional, desamparado de toda asistencia pública, si bien las corrientes migratorias norteafricanas y de otros lugares hacia la próspera Europa occidental -pakistaníes al Reino Unido, surinameses a Holanda,turcos a Alemania, magrebíes a Francia y España, etcétera- parecen mantener la existencia de un componente proletario en el seno de la sociedad europea occidental. Todo parece indicar que este elemento exógeno aumentará de tamaño, dadas las tendencias demográficas estacionarias de nuestras poblaciones indígenas.

La indeterminación y fluidez del sistema de rangos en Europa refleja no sólo la aceleración de los procesos de mudanza social, sino también la institucionalización gradual del reclutamiento en base al mérito en sociedades con sistemas universales de educación. De otra parte, el denominado "aburguesamiento" de la clase trabajadora europea en los últimos decenios ha trasladado el foco de análisis de los trabajadores desde una perspectiva productiva a una pronunciadamente consumista. A pesar de ello, ha cambiado la relación de este sector de la sociedad civil con el estado. A mayor asistencia pública, mayor dependencia estatal de éste último.

Es notoria también la progresiva tercialización de las clases trabajadoras europeas. Dado que la oferta de empleo calificado ha aumentado significativamente en los últimos tiempos, las oportunidades que se presentan para los trabajadores calificados -y, en especial, las mujeres- de ser absorbidos por el sector productivo de los

[9] En su clásica obra La nouvelle classe ouvrière, (Paris: Seuil, 1963), ed. castellano: La nueva clase obrera, (Madrid: Tecnos, 1969), Serge Mallet calificó a dicha sección de los asalariados como la "aristocracia de los trabajadores". 
servicios han sido muy considerables. Si bien la movilidad dentro de la clase trabajadora ha estado mediatizada durante largo tiempo por la dicotomía trabajo manual/trabajo no manual, la promoción individualizada de los trabajadores se ha visto facilitada por un mayor abanico de oportunidades ocupacionales abierto al amplio espectro de la clase trabajadora. Ello ha sucedido así, particularmente, con referencia a los miembros más jóvenes ya que para ellos al acceso a las "carreras" ha sido más fluido. Otro aspecto de este proceso ha sido el problemático acceso de esos jóvenes al mercado de trabajo que se vio fuertemente restringido tras la recesión económica en 1973. En los últimos años la tendencia a la baja del desempleo en los países de la Comunidad Europea ha sido sensible, aunque existen bolsas de trabajadores (20-30 años), tanto manuales como no manuales, que siguen encontrado grandes dificultades para incorporarse al proceso productivo. La corriente de innovaciones tecnológicas no siempre favorece tal incorporación, si bien el crecimiento de los servicios asistenciales, las industrias del entretenimiento -sobre todo el turismo- y la duración de los estudios -muchos de ellos de "reciclaje" o de adultos- absorbe cifras cada vez más altas de gentes que, de no sẹr así, estarían potencialmente "paradas". Los programas gubernamentales de empleo juvenil potencian, una vez más, el del peso del estado dentro del mercado libre y autónomo de la sociedad civil.

La institucionalización de los conflictos de clases en Europa, a través de la sindicalización y los partidos políticos de izquierda, ha incidido en una pretendida despolitización de la clase trabajadora. Los conflictos de clase en la Europa de toda la segunda parte del siglo XX han respondido a una forma de competición social que se hace necesaria cuando grupos numerosos de ciudadanos no consiguen concretar sus intereses personales mediante su sola acción individual. No obstante, y como reacción, en los últimos tiempos asistimos a una idealización cultural de la fuerza individual como instrumento de promoción social, lo que ha tenido como derivación una atenuación de los conflictos de clase de carácter amplio y colectivo. No obstante, lo más descollante en la Europa contemporánea es la relativa institucionalización de pactos y acuerdos entre colectivos -no necesariamente a nivel estatal, sino dentro de empresas o ramas de actividadpara establecer repartos de responsabilidades de trabajo, remuneración y condiciones laborales. 


\subsection{Viejas y nuevas clases medias}

La delimitación de las clases medias y el establecimiento desus límites de inclusión y exclusión constituyen un problema de no fácil resolución. Si bien ambas clases, trabajadora y media, se componen de múltiples estratos, se puede observar una mayor solidaridad de carácter estable y duradero en la clase trabajadora -por tenue que pueda apreciarse- que en la clase media. Las alianzas entre los diferentes estratos de las clases medias son a menudo efímeras y a veces caleidoscópicas, con frecuencia según los intereses de cada estrato en relación a sus posicionamientos políticos y económicos dentro de la sociedad. En todo caso, la solidaridad profesional, ocupacional ("de cuerpo") o corporativa parece ser más potente que la que pueda unir o movilizar a cada segmento de clase.

Las clases medias en la Europa posterior a la Segunda Guerra Mundial han incrementado su tamaño de manera incesante, en abierta contradicción con algunos vaticinios radicales que presumían una polarización de dichos sectores intermedios de la sociedad hacia las clases trabajadora y alta. Sí cabe distinguir, en cualquier caso, una nueva clase media ${ }^{10}$ diferenciada de la tradicional, compuesta por tenderos, comerciantes, pequeños empresarios y profesionales liberales. Dicha nueva clase media fue ya identificada en el período de entreguerras en Europa como un estrato compuesto primordialmente por empleados calificados del sector privado y funcionarios de la administración pública. En la actualidad incluye empleos tales como los técnicos de la industria, los docentes universitarios, los gerentes de tipo medio y algunos sectores terciarios. Muchos están vinculados al sector público lo cual, una vez más, mengua el volumen de población estrictamente confinado a la sociedad civil, es decir, el ámbito privado.

En los últimos decenios, el considerable incremento de las nuevas clases medias, unido a su supuesta "desconcienciación" clasista, ha inducido a algunos observadores a concluir que dicho estrato nuevo es un grupo desclasado y aún en estado de descomposición.

[10]Aunque el término "nueva clase media" ya fue usado por Gustav Frieđich von Schmoller en 1897, su primera conceptualización se atribuye a Emil Lederer y Jacob Marschak (Der Neue Mittelstand, Tubunda, 1926), quienes disgnosticaron la existencia de un nuevo estrato social desgajado de las tradicionales clases medias. 
Sucede, empero, que a pesar de sus mayores oportunidades de ascenso social y su mayor relación con los grupos delimitados por ocupaciones en vez de por factores de clase, muchos miembros de esas clases medias se autoubican de manera subjetiva en dicho estrato social, amén de su notoria capacidad -ya señalada- por acceder a puestos de alta responsabilidad y retribución, y luego mantener o mejorar, en su prole, el lugar de privilegio, ingresos y autoridad.

Respecto a las clases medias tradicionales debe reseñarse un declive cuantitativo. No obstante, la heterogeneidad de la clase media en su conjunto es, probablemente, su rasgo característico en la Europa occidental de nuestros días. Los miembros de las capas medias -los ceti medi, en italiano- se entremezclan pero no se funden. Así, por ejemplo, el desarrollo de nuevas profesiones (técnicos en telecomunicaciones, expertos en cibernética, analistas de sistemas, economistas, consultores de empresas de vanguardia) ${ }^{11}$ no ha entrañado su absorción por las viejas clases medias, a pesar de que la filosofía de vida de las "viejas" profesiones liberales ha atraído sobremanera a los miembros de las nuevas clases medias, que los imitan en parte al intentar resaltar su recién adquirido rango social. La pauta histórica de "imitación hacia arriba", que otrora ejerciera la burguesía con la antigua nobleza, y luego la pequeña con la alta burguesía, encuentra. hoy su eco en el esfuerzo de yuppies y demás grupos ascendentes por consolidarse en estratos privilegiados de fuerte exogamia con las clases dominantes y la adquisición ulterior de su estilo exclusivo (es decir, excluyente) de vida. ${ }^{12}$

Diferencias en los estilos de vida y en las diversas pautas de interacción social (pertenencia a clubes o asociaciones de tipo restringido, capacidad y orientación del consumo individual) establecen la demarcación entre las subclases medias y entre éstas y las altas. Claro está que sus correspondientes subculturas se han ido aproximando gradualmente en los últimos años y su fusión, a mediano o largo plazo, no cabe descartarse por completo. Dejando aparte consideraciones de tipo coyuntural entre las "nuevas" $y$ "viejas" clases

[11]Se trata de los nuevos "cuadros", u ocupaciones semiejecutivas o hasta ejecutivas bien remuneradas, cuya presencia ya era obvia en los años '60. Cf. edición especial de La Table Ronde: "Le phénomène 'cadres", NN 253, febrero 1969, París.

[12]Cf. W. G. Runciman, Relative Deprivation and Social Justice, (Londres: Routledge \& Kegan Paul, 1966). 
medias, el conjunto del estrato medio de la sociedad europea occidental de los últimos tiempos se ha caracterizado por un especial énfasis en la competición individualista, la privatización y su orientación social hacia el logro económico. Ello ha ido acompañado de un cierto antiestatalismo -antiintervencionismo- que ha inclinado a algunos a hablar, en tonos neoliberales, de un resurgir o retorno de la sociedad civil. Pero no hay que confundir la efervescencia de una clase o categoría con tendencias socioestructurales más profundas.

Otra característica notable de un cierto arquetipo de familia de clase media europea es la aceptación de sacrificios económicos a corto plazo, con el fin de procurar una esmerada educación para sus hijos y mejorar, de paso, sus futuras oportunidades a mediano y largo plazo. Ello incide sobremanera en las pautas de reproducción y promoción sociales que enmarcan un mayor dinamismo comparativo de las clases medias en contraste con otras, tal vez más fatalistas o resignadas a su posición social subordinada. Cabe destacar, asimismo, la mayor propensión de las mujeres casadas, o sin vínculo matrimonial, a trabajar fuera de casa. No es de extrañar, pues, que licenciadas universitarias de aquellos estratos medios y superiores de la clase media tengan más posibilidades de encontrar empleos estables que las mujeres de la clase trabajadora. Ese segundo salario que se incorpora a la unidad familiar no sólo marca las diferencias de consumo respecto a otros grupos sociales menos favorecidos económicamente, sino que permite a sus descendientes un acceso más selectivo a una educación exclusiva duradera y esmerada, al margen del ciclo de enseñanza pública y gratuita.

El comportamiento asociativo y político de las clases medias es variado. Es cambiante electoralmente. Los partidos liberales, que tradicionalmente obtuvieron su mayor respaldo de las pequeñas burguesías medias, han perdido mucha de su pasada influencia. En cambio, los partidos socialistas y socialdemócratas, al moderarse, han recibido en ocasiones un apoyo explícito de aquellos grupos. Se alude a menudo a la propensión de las. clases medias a adocenarse y aburguesarse en su comportamiento electoral y político. No pocos politólogos, por ejemplo, resaltan la fidelidad de las clases medias del sur de Inglaterra a la política neoliberal y conservadora. Sin embargo, cabe resaltar igualmente el carácter radical de la acción social y política de amplios sectores de las clases medias británicas. Así, durante los años 60 y 70 , el importante movimiento antinuclear 
pacifista del Campaign for Nuclear Disarmament (CND) se nutrió fundamentalmente de miembros de aquellos estratos sociales. En España, durante lạ Segunda República (1931-1939), un sector muy considerable de las clases medias apoyó activamente las opciones republicanas radicales de centro y de izquierda. El radicalismo de clase media continúa siendo un factor importante en la Europa de hoy. Tanto el Partido Radical Italiano -años 70 y 80- como los movimientos ecologistas y pacifistas de toda la Europa finisecular, tienen fuertes raíces en las clases medias en todos sus niveles, altos y bajos. Digamos que son la parte más militante de la sociedad civil contemporánea, en contraste con la cautela de ciertos grandes partidos políticos, más vinculados al estado y a la función pública.

La conducta política ambigua, y a veces errática, de las clases medias europeas ha mediatizado profundamente la acción de los partidos de derecha e izquierda que cortejan afanosamente el favor electoral de sús cruciales "votos flotantes". Aunque debería evitarse la conclusión de que la configuración política de las capas medias de la sociedad no es clasista, sí conviene resaltar el hecho de que, en condiciones de prosperidad, su conformación como clase aparece cuando menos difusa y menos caracterizable.

\subsection{Clases altas y élites europeas}

Posiblemente el rasgo más sobresaliente de las clases altas europeas siga siendo su endogamia, que representa una forma de conservación de sus capitales y de su ventajosa posición social. Otros signos externoscaracterísticos de estos grupos son su internacionalismo y cosmopolitismo. La influencia sociocultural de estas élites económicas representa una de las barreras más impermeables a la movilidad social generalizada. $^{13}$

Tradicionalmente la clase alta ha respondido al clásico análisis de Gaetano Mosca: ${ }^{14}$ económicamente rica, políticamente influyente y cuasi poseedora del monopolio en el reclutamiento de las élites

[13]Para una consideración general reciente de cuestiones de movilidad social con abundantes datos para países europeos, cf. L. Chacón, iMovilidad social o rayectoria de clase?, (Madrid: CIS, 1989).

[14]Curiosamente Gaetano Mosca no habla explícitamente sobre "elitismo" en ninguna de sus dos obras más relevantes: Sulla teorica del governo e governo parlamentare (1884) y Elementi di scienza política (1986). Para las polítican, en relación al dominio de una minoría social sobre la mayoría desorganizada, cf. Scritti politici di Gaetano Mosca, a cargo de G. Sola, vol. 2, Turín; Utet, 1982. 
políticas dirigentes. Sin embargo, y tras la Segunda Guerra Mundial, hemos asistido a una progresiva interferencia en el poder tradicional de las clases altas por parte de la acción del estado asistencial (welfare state), a través sobre todo de la introducción de impuestos progresivos sobre ganancias de capital y el aumento exponencial del contrapoder representado por los altos gerentes y ejecutivos de empresas y corporaciones.

En línea con la definición de élite de Raymond Aron, ${ }^{15}$ como aquella minoría que ejerce la función de gobierno de la comunidad, debe observarse como un rasgo característico de las democracias europeas la coexistencia de múltiples grupos de minorías dirigentes. A las élites tradicionales, como la política (parlamentarios, ministros, dirigentes de partidos políticos y sindicatos), la burocrática (altos funcionarios de las administraciones públicas), la militar (cúpula de las fuerzas armadas y de seguridad) y científica (asesores económicos e investigadores de tecnologías de vanguardia), habría que añadir la formada por los altos ejecutivos de las empresas, como se ha señalado anteriormente. A ellos cabría añadir con cautela la élite intelectual de cada país, cuyo peso o influencia varía considerablemente según las características socioculturales y la presencia de tradiciones críticas o acomodaticias en su seno. ${ }^{16}$ Además, en la actualidad asistimos a la conformación social de nuevas élites de poder económico que no son de extracción patrimonial. Su influencia se trueca a menudo en poder real a la hora de intervenir, por ejemplo, en los flujos financieros transnacionales o en fijar estrategias de localización industrial de fuerte impacto espacial.

Los sistemas políticos de la Europa occidental producen sus propias élites de poder que se estructuran verticalmente y que presionan continuamente por ocupar su lugar en los centros decisorios. Se configura, de tal manera, un tipo de pluralismo transversal que a mienudo va parejo con el pluralismo cultural, ideológico, religioso y hasta económico de muchas sociedades europeas. No obstante tal pluralismo debe entenderse como amortiguado por las características culturales del pragmatismo y relativismo que son rasgos de la hiper-

[15]R Aron, "Social Stratification and the Ruling Class", 1a. parte, Sociological Review, vol. 1, NN2, marzo 1950, p. 9.

[16]E. Shils, The Intellectuals and the Powers, (University of Chicago Press, 1972). 
modernidad. La existencia de este tipo de pluralismo vertical no implica necesariamente una participación "armoniosa" de las élites en el proceso de toma de decisiones políticas. En cambio, sí responde a un tipo menos coercitivo que el constituido por sistemas donde una sola clase o un partido político único detenta el monopolio del poder estatal.

En cualquier caso, el pluralismo elitista queda restringido en la Europa occidental por la naturaleza clasista de una buena parte de sus sociedades. Las estructuras ocupacionales de éstas y sus instituciones sociales siguen estando condicionadas -a pesar de ser mucho menos rígidas- por el mantenimiento de rangos y privilegios que son los primeros responsables de la desigualdad y de las injusticias que genera.

\section{El futuro social de Europa}

A pesar de que las libertades individuales de la civilización liberal continúan vigentes en las constituciones de los países de la Europa occidental, las libertades colectivas de tipo gremial (partidarias, sindicales, asociativas, corporativas) han recobrado ímpetu en los últimos tiempos. Nos encontramos, con ello, en una situación así paradójica. A un indudable avance de la estatización en Europa no ha correspondido una baja neta de la densidad asociativa en la sociedad civil. Al contrario, merced al marco constitucional liberal común a toda Europa occidental, hay una proliferación de asociaciones autónomas de la más diversa índole -económicas, deportivas, culturales, ecologistas, científicas, etcétera- que atestiguan el vigor de la tradición civil voluntarista y "autonomista" de la civilización europea.

La corporatización y estatización relativa de las modernas sociedades de la Europa occidental se perciben más en el nivel estructural -donde han debilitado en parte la fuerza de la sociedad civil burguesa- que en el cultural. El paso de la competitividad individualista empresarial a la nueva, ocupacional y corporativa, ha significado que las calificaciones personales y los derechos a la autonomía profesional individual han sido más respetados. No obstante, si bien la 
organización sindical es una de las defensas más eficaces contra los daños que pueda infligir el mercado libre de trabajo a obreros y empleados, la sindicación por su parte puede también convertirse en una fuente de anquilosamiento del movimiento obrero a través del excesivo corporatismo. Puede decirse que, a pesar de múltiples conflictos, predomina la articulación de los intereses colectivos organizados (asociaciones, sindicatos, equipos profesionales, gremios, banca, etcétera) sobre la concurrencia individualista y fragmentaria universal.

Aunque hemos hecho ya varias alusiones al fenómeno de las pronunciadas variedades de las sociedad civiles europeas, conviene insistir sobre él una vez más. Contra la opinión de quienes, apoyándose en la evidente diversidad social interna de los países europeos y en las diferencias internacionales, insisten en negar la convergencia social paulatina, existen datos abundantes que apuntan hacia la realidad de tal convergencia. Se trata, naturalmente, de un proceso lento, complicado y multidireccional. Sicilia, por ejemplo, no se acerca al mismo ritmo hacia la nueva estructura social que caracteriza a Lombardía y Piamonte, ni Andalucía lo hace hacia lo que caracteriza a Cataluña. Para complicar más las cosas, hay regiones industriales -con predominio de industria extractiva o pesada- que sufren desindustrialización -Yorksshire, Asturias, Valonia-, sin reconversión industrial adecuada y, por lo tanto, se encuentran con un debilitamiento de su tejido social a través del paro. Otras regiones en cambio-Madrid, Lyon, el "corredor" Londres/Bristol- se enriquecen con industrias punteras, laboratorios de $I+D$, centros universitarios y de alta tecnología, etcétera. Todo ello significa una reordenación del mapa social europeo. Convergencia no significa homogeneización. Denota un proceso de acercamiento a una cierta estructura social, con sus desigualdades y variedades internas. Esta convergencia va en paralelo a un hecho sin precedentes en la historia de los pueblos europeos occidentales desde fines de la Edad Media: la comunidad de sus instituciones políticas, económicas y formas de vida. Así todos ellos se rigen por democracias liberales constitucionales, sus sociedades están desarrolladas económicamente (Grecia y Portugal son excepciones muy parciales), todos tienden con altibajos a la meritocracia y casi todos ellos se hallan en un proceso de mutua 
integración política, financiera y de comunicaciones. El proceso -siempre más lento- de convergencia social ocurre en paralelo y en relación con todo ello, pero es en muchos sentidos indudable. ${ }^{17}$

En las postrimerías del siglo, se percibe una sustitución parcial de la tradicional dicotomía esfera pública/esfera privada por otra nueva, superimpuesta, que sería la de la esfera corporativa/esfera cívica. Así, los nuevos movimientos sociales (alternativos, antiburocráticos y no integrados en la esfera corporativa) bien podrían incrementar su fuerza en vez de ser constituirse como una mera moda pasajera. ${ }^{18}$ En consecuencia la sociedad civil europea no es ya la misma que la de la época en que vino a constituirse de un modo históricamente paradigmático. Pero tampoco ha desaparecido. Si bien no es posible una vuelta a aquella sociedad civil de ayer, la gran vitalidad que muestran las sociedades europeas contemporáneas a fines del siglo $\mathrm{XX}$, tras un largo período de turbulencias y conflictos bélicos entre sí, es esperanzadora. ${ }^{19}$. La sociedad civil europea fue concebida por sus filósofos como el ámbito de la civilidad, de la paz y del ejercicio de la excelencia humana. Acabamos de ver hasta qué punto distamos los europeos de acercarnos a ese ideal de nuestros mayores. Pero nada nos impide seguir en el empeño.

[17]H. Kaelble, Auf dem Wege zur einer europäischen Gesellschaft, (Munich: C. H. Beck, 1987). [18]Cf., por ejemplo, las tesis de Johan Galtung en "The Green Movement: A Socio-Historical Exploration ", en: International Sociology, vol. 1, №1, marzo 1986, pp. 75-90.

[19] Sobre los avances y retrocesos de la sociedad civil en el momento presente, cf. Fundación F. Ebert/Instituto Fe y Secularidad (comps.), Sociedad Civil y Estado. ¿Retomo o reflujo de la sociedad civil?, (Madrid: Fundación F. Ebert, 1989.). Ensayos de J. L. Aranguren, F. J. Laporta, J. J. Linz, I. Sotelo, E. Díaz, A. G. Santesmases, A. Cortina, A. Duato y L. de Sebastián. También J. Keane, Divil Society and The State, (Londres: Verso, 1988). 